\title{
A Review of the Current Level of Support to Aid Decisions for Migrating to Cloud Computing
}

\author{
Adel Alkhalil \\ Faculty of science and Technology \\ Reza Sahandi \\ David John \\ Bournemouth University \\ Poole, Dorset, BH12 5BB, United \\ Kingdom \\ Faculty of science and Technology \\ Bournemouth University \\ Poole, Dorset, BH12 5BB, United \\ Kingdom \\ aalkhalil@bournemouth.ac.uk \\ rsahandi@bournemouth.ac.uk
}

\begin{abstract}
Cloud computing provides an innovative delivery model that enables enterprises to reduce operational costs and improve flexibility and scalability. Organisations wishing to migrate their legacy systems to the cloud often need to go through a difficult and complicated decision-making process. This can be due to multiple factors including restructuring IT resources, the still evolving nature of the cloud environment, and the continuous expansion of the services offered. These have increased the requirement for tools and techniques to help the decision-making process for migration. Although significant contributions have been made in this area, there are still many aspects which require further support. This paper evaluates the existing level of support to aid the decision-making process. It examines the complexity of decisions, evaluates the current state of Decision Support Systems in respect of migrating to the cloud, and analyses three models that proposed support for the migration processes. This paper identifies the need for a coherent approach for supporting the whole decision-making process. Further, it explores possible new approaches for addressing the complex issues involved in decision-making for migrating to the cloud.
\end{abstract}

\section{Keywords}

Cloud computing, cloud migration, Decision-Making Process, cloud decision support, cloud knowledge base system

\section{INTRODUCTION}

The attractiveness of cloud-based services due to their advantages, particularly the reduction of capital expenses and the virtually infinite resource capacity has motivated many enterprises to migrate their applications to the cloud [1]. According to Sahandi et al. [2] many enterprises are very interested in cloud computing that will enable them to reduce costs, improve flexibility and scalability. Established companies as well as start-ups view the cloud as a valuable opportunity that offers a competitive edge and allows to meet their business objectives more effectively $[1,3]$.

(C) 2016 Association for Computing Machinery. ACM acknowledges that this contribution was authored or co-authored by an employee, contractor or affiliate of a national government. As such, the Government retains a nonexclusive, royalty-free right to publish or reproduce this article, or to allow others to do so, for Government purposes only.

ICC '16, March 22-23, 2016, Cambridge, United Kingdom (c) 2016 ACM. ISBN 978-1-4503-4063-2/16/03 ...\$15.00

DOI: http://dx.doi.org/10.1145/2896387.2896443
Organisations are usually interested in moving only some of their systems to the cloud. This is because not all applications can be easily migrated due to specific restrictions or requirements, for example, safety-critical software [4]. Unlike start-ups that develop systems from scratch, organisations planning to migrate their legacy services to cloud computing often need to deal with what is called 'brownfield development' where new services have to inter-operate with their systems [5, 6]. Therefore, organisations wishing to migrate legacy systems to the cloud often need to go through a difficult and complicated decision-making process. Although, a significant attention has been paid by many to the need for supporting the migration decisions, they remain difficult $[7,8]$. The main problem in their approaches is the separation of elements in migration processes that are connected and dependent on each other. Further, the existing support is usually limited to the selection of providers such as [5] or to the adaption required for migrating applications such as [4].

Despite the development of many approaches to aid the decisions of migrating to the cloud, limited work has been done to review the level of support offered by the current approaches. This has made it difficult to assess whether the current approaches can address the complex issues involved in the process of migrating to the cloud.

This paper reviews the current situation with regard to the decisions of migrating to the cloud. It aims to evaluates the level of support offered by the existing approaches, identify the areas that require support in the decision-making process of migrating to the cloud, and suggest possible new approaches to address its complexity.

The paper is structured as follow: Section 2 provides an overview of decision-making process, defines the migration to cloud computing, and investigates the complexity of migration decisions. Section 3 summarizes the current situation with regards to the existing Decision Support Systems (DSS) designed to aid cloud migration projects. Section 4 provides an analysis of three models to support the process of migration to the cloud. Section 5 discusses two approaches to address the complex issues involved cloud migration process. Finally, Section 6 provides the conclusion.

\section{BACKGROUND}

\subsection{Decision making process}

According to Simon [9], the context of organisational decision situations and bounded rationality of individuals demand following a structured process in organisational decision making. In his suggested model of organisational decision making process, 
he divides it into three major phases: Intelligence, Design, and Choice. The process starts with the intelligence phase where the 'reality' of the organisation is examined. This involves problem identification and information gathering activities about the societal, the competitiveness, and the organisational environments. The design phase simplifies the organisation's "reality" and identifies relationships between variables, as well as setting the criteria for evaluating alternative courses of action. The choice phase is to select the most appropriate alternative course of action based on the criteria identified in the design phase. Simon's model has been widely accepted and adopted as a problemsolving model [10]. It can be used for individual as well as group decisions. Turban et al. [11] described Simon's model as the most concise, and yet complete characterisation of rational decision making.

Sections 3 provides an analysis of the exiting DSSs designed to support the decision making process for migrating to cloud computing based on the three levels in Simons' model [9].

\subsection{Migration to cloud computing}

Migration to the cloud, for the purpose of this paper, can be defined as the transitioning process of all or part of an organisation's legacy IT resources, including: hardware, software, stored data, and business processes, from locally on-premises deployments behind its firewalls to the cloud environment where they can be managed remotely by a third party. The process also encompasses the shifting of IT resources between different cloud providers; this process is known as cloud-to-cloud migration. The cloud migration process may involve retaining some IT infrastructure on-site [12].

The motives of organisations for considering cloud migration are usually to gain a competitive edge, improve efficiency, business agility, and innovation. Migration to cloud computing can be a strategic decision for organisations to enhance the development of these goals through improving scalability, flexibility, and time to market.

\subsection{The complexity in the decisions of migrating to the cloud}

Decisions regarding migration to cloud computing are inherently complex, because they are influenced by a number of inconsistent criteria such as cost and quality of services [13]. Conducting an evaluation of the benefits, risks and costs is also far from straightforward [14]. Further, the shift towards the cloud is likely to result in considerable changes in how IT services are developed, deployed, supported, and paid for [15]. This has led to the need for organisational and socio-technical factors to be taken into account during the decision making process [14]. Further, outsourcing projects are difficult to evaluate because adequate outcome feedback can only be obtained after implementation [16]. Menzel et al. [17] pointed out that migration to cloud computing is a decision-making problem that requires identification of criteria and value-driven comparison of alternatives with respect to the criteria selected. Andrikopoulos et al. [18] also pointed out that migrating to the cloud is a multi-dimensional problem with multiple decision points that may create various analytical tasks and interconnected feedback loops.

Andrikopoulos [19] stated that as cloud computing represents a fairly new paradigm; there is still a significant number of issues and risks within the process of migration. They may include: loss of privacy, disruption to business processes, legal implications, change to the systems management, problems with interoperability, data integrity, application portability, business continuity, staff productivity, and security issues [2, 21, and 22]. The Cloud Security Alliance [23] identified seven security threats of cloud computing. These threats had led to wide concerns about the availability and accessibility of cloud-based services. The lack of standards in cloud computing also rise interoperability and manageability issues inside and between cloud providers which may increase the likelihood of vendor lock-in with possible economic impacts [2]. The complexity and lack of transparency with respect to cost and quality are further challenges for many [21]. Another factor that influences the complexity of migration decisions is the availability of vast numbers of cloud-based services, configurations, and providers and lack of cloud standards and regulations [24]. According to García-Galán [25] there are over 100 public cloud providers associated with a considerable number of confirmations, for example Amazon web services has 16.991 different configurations. Another dimension is the need for service design and adaptation. According to Bergmayr et al. [26] the systematic and efficient modernisation of legacy applications to exploit current cloud-based technologies remains a major challenge. Failure or incorrect adaption might result in difficulties in meeting some quality or economic requirements [27]. Typical adaptation problems range from compatibility and performance issues to licensing that may forbid organisations from moving registered software components.

Therefore, making the decision of whether and how to migrate existing systems to the cloud can be difficult. It requires the consideration and evaluation of a wide range of technical and organisational aspects. Successful cloud migration would require a clear understanding of the cloud environment, careful planning, system analysis, and execution to ensure the cloud solution's compatibility with organisational requirements, while maintaining the availability and integrity of the organisation's IT systems [14]. Further, migration to the cloud environment requires more emphasis on business design where cloud service will interface with business systems. Therefore, the success of cloud computing is mainly based on the efficient implementation of the architecture [28]. The range of cloud-based services currently offered by vendors is growing simultaneously with the emergence of varying cloud service providers. Consequently, along with the utilisation strategy, it is important to perceive which services are desired. These requirements for consideration during the decision-making process resulted in confusion in how to migrate existing systems and which service provider to choose. Moreover, this confusion is usually associated with a lack of expertise to manage and understand the cloud's configurations and operational metrics. These have increased the requirements for supported migration decisions. In the following section we evaluate the current state of support in this regard.

\section{A REVIEW OF THE EXISTING CLOUD DSSs}

The increasing complexity of the decisions to migrate to the cloud (section 2.3), alongside the evolution and popularity of cloud computing, has led to significant attention being paid by many industrialists and academics to the need for supported migration decisions. Cloud vendors and IT consultancy agencies have made several attempts to address the demand for supported migration decisions with a number of whitepapers, guidelines, and assessment tools. However, these attempts have either been developed for marketing purposes or they are not publicly 
available, because they are based on closed proprietary technologies that usually require consultancy contracts [14]. In Academia also, a wide range of DSSs were proposed (See Table 1). However, the majority of the existing DSSs concentrate on the evaluation and selection of cloud providers with cost being the main factor. In other words, these systems focus on supporting decisions at the choice level by evaluating services providers.

The approaches proposed in [5], [20], [25], and [28] focus on the selection of service providers for Infrastructure as a Service (IaaS). Khajeh-Hosseini et al. [5] developed a cloud adoption toolkit that analyses the suitability of the technology, consumption of energy, cost, impacts of stakeholders and operational viability. It incorporates two decision support tools: cost calculation and risk-benefit analysis [14].

Menzel et al. [20] developed the CloudGenius that provides a multi-criteria approach to support the selection of providers for IaaS. It allows users to define their multiple requirements to be matched against a knowledge-base of cloud service providers. The CloudGenius leverages an evaluation and decision-making framework, called (MC2) [29] to support requirements and adopt a profound multi-criteria evaluation approach. Santiago [28] focused on the evaluation of the IaaS providers based on their performance and costs for migrating a workflow-based simulation environment. García-Galán et al. [25] focused on supporting the decision-making for selecting the most suitable cloud configuration of an IaaS.

Garg et al. [24] designed the Service Measurement Index (SMI), aimed to reduce the difficulties of selecting providers based on their quality of service attributes. SMI attributes are designed based on the International Organisation for Standardisation (ISO) standards by the CSMIC consortium. These attributes are evaluated through the use of the Analytical Hierarchy Process (AHP) mechanism.

The proposals in [4], [18], [27], [30], [31], and [32] aimed to support the migration of applications to the cloud. In [4] the need for adaptation to operate in the cloud environment was taken into account and the selection of a cloud offering that address the requirements of an application was considered in [18]. Andrikopoulos et al. [30] proposed a DSS to select the cloud offerings for migrating applications that best match the parameters defined by users. Four factors were taken into account (See Table 1). They influence each other, and are dependent on 7 tasks (work load profiling, compliance assurance, performance prediction, cost analysis, identification of security concerns, identification of acceptable QoS levels, and effort estimation).

Juan-Verdejo et al. [27] developed InCLOUDer that is a DSS to aid organisations in the process of adapting applications to the cloud environments. The InCLOUDer enables organisations to describe their migration criteria, the architecture, properties, and the requirements of their applications. The InCLOUDer provides a taxonomy of organisations' criteria related to cloud migration including: accountability, agility, assurance, cost, performance, security and privacy, and usability and follows the analytical hierarchy process to trade off.

In [31] the database layer of an application was taken into account to support the migration. The database layer provides data persistence and manipulation capabilities, which is necessary to address aspects such as differences in the granularity of interactions and data confidentiality, and to enable the interaction of the application with remote data sources. It considers incompatibility identification and resolution, support for refactoring of the application architecture, security, and reusability.

Juan-Verdejo and Baars [32] proposed a decision support system for partially migrating an application to the cloud. Applications are usually subject to strict requirements such as privacy, security and compliance. They are also embedded into complex enterprise IT architectures with a multitude of interdependencies. For these reasons, a hybrid (local/cloud infrastructure) deployment might be the solution where only suitable components for the cloud environment are migrated.

Frey and Hasselbring [33] developed the cloudMIG to migrate legacy software systems to the cloud environment. It includes six main activities represent the current software architecture, selecting the target architecture, and adaptation. It aims to classify the suitability of cloud environments for a specific system and the level of configuration for a reengineering process. It uses the cloud-based software Eucalyptus and the e-commerce ERP systemApache OFBiz.

A different approach was taken by Misra and Mondal [34] to support the decisions for migration. They considered aiding organisations in identifying the suitability of existing companybased IT resources for the cloud and the feasibility of migrating to the cloud environment.

Table 1. A review of the existing cloud DSSs

\begin{tabular}{|c|c|c|c|c|}
\hline $\begin{array}{l}\text { Proposed } \\
\text { approach }\end{array}$ & $\begin{array}{l}\text { Cloud } \\
\text { service }\end{array}$ & Factors taken into account & Method & $\begin{array}{l}\text { Level of } \\
\text { support }\end{array}$ \\
\hline $\begin{array}{l}\text { Suitability } \\
\text { analysis for cloud } \\
\text { computing [34] }\end{array}$ & $\begin{array}{c}\text { Not } \\
\text { specified }\end{array}$ & $\begin{array}{l}\text { Size of the IT resources, the } \\
\text { utilisation pattern of the resources, } \\
\text { sensitivity of the data, and criticality } \\
\text { of the service }\end{array}$ & ROI model & Design \\
\hline CloudMIG [33] & $\begin{array}{l}\text { PaaS and } \\
\text { IaaS }\end{array}$ & Applications reengineering & $\begin{array}{l}\text { Mathematical } \\
\text { modelling }\end{array}$ & $\begin{array}{l}\text { Design and } \\
\text { Choice }\end{array}$ \\
\hline $\begin{array}{l}\text { Cloud adoption } \\
\text { toolkit [5] }\end{array}$ & IaaS & $\begin{array}{l}\text { Cost, characteristic social factors, } \\
\text { political factors, performance, and } \\
\text { practicalities }\end{array}$ & UML & Choice \\
\hline $\begin{array}{l}\text { DSS for migrating } \\
\text { applications [30] }\end{array}$ & SaaS & $\begin{array}{l}\text { Applications distribution, cloud } \\
\text { providers selection, elasticity } \\
\text { strategy, multi-tenancy requirements. }\end{array}$ & $\begin{array}{l}\text { Three-tiered } \\
\text { architecture }\end{array}$ & $\begin{array}{l}\text { Design and } \\
\text { Choice }\end{array}$ \\
\hline $\begin{array}{l}\text { DSS for migrating } \\
\text { applications [18] }\end{array}$ & SaaS & Cost and providers' characteristic & $\begin{array}{l}\text { Conceptual } \\
\text { modelling }\end{array}$ & Choice \\
\hline $\begin{array}{l}\text { Applications } \\
\text { adaptations for the } \\
\text { cloud environment } \\
\text { [4] }\end{array}$ & SaaS & The need for adaptation & $\begin{array}{l}\text { Holistic } \\
\text { approach }\end{array}$ & Design \\
\hline $\begin{array}{l}\text { partially migration } \\
\text { of applications to } \\
\text { the cloud [32] }\end{array}$ & SaaS & Hybrid deployment & $\begin{array}{l}\text { Component } \\
\text { placement a } \\
\text { and AHP }\end{array}$ & $\begin{array}{l}\text { Design and } \\
\text { Choice }\end{array}$ \\
\hline SMICloud [24] & $\begin{array}{c}\text { Not } \\
\text { specified }\end{array}$ & $\begin{array}{l}\text { Accountability, agility, assurance, } \\
\text { cost, performance, and security and } \\
\text { privacy. }\end{array}$ & $\begin{array}{l}\text { Component } \\
\text { placement a } \\
\text { and AHP }\end{array}$ & Choice \\
\hline InCLOUDer [27] & SaaS & $\begin{array}{l}\text { Applications adaptations and } \\
\text { Accountability, agility, assurance, } \\
\text { cost, performance, and security and } \\
\text { privacy. }\end{array}$ & AHP & $\begin{array}{l}\text { Design and } \\
\text { Choice }\end{array}$ \\
\hline $\begin{array}{l}\text { DSS for migrating } \\
\text { applications [31] }\end{array}$ & $\begin{array}{l}\text { SaaS and } \\
\text { PaaS }\end{array}$ & The database layer of an application & $\begin{array}{l}\text { Step-by-step } \\
\text { methodology }\end{array}$ & Design \\
\hline CloudGenius [20] & IaaS & $\begin{array}{l}\text { Cost, Performance, providers' } \\
\text { characteristic }\end{array}$ & $\begin{array}{l}\text { AHP and } \\
\text { mathematical } \\
\text { modelling }\end{array}$ & Choice \\
\hline $\begin{array}{l}\text { Configuration } \\
\text { support [28] }\end{array}$ & IaaS & Cost and providers' characteristic & Feature model & Choice \\
\hline $\begin{array}{l}\text { Workflow } \\
\text { Infrastructure } \\
\text { migration [25] }\end{array}$ & IaaS & Cost and providers' characteristic & $\begin{array}{c}\text { OPAL } \\
\text { Simulation }\end{array}$ & Choice \\
\hline
\end{tabular}

The review shows that the vast majority of the existing DSSs do not support the assessment of the current cloud environments and 
business processes. In other words, they focused on supporting the migration at the choice level. Although, evaluation of providers and their appropriate selection are critical, making an informed decision to migrate requires the analysis of a wide range of factors at early stages of a decision process. Companies should become fully aware of the cloud environment capabilities, regulations, potentials and threats before coming to a decision. Almost none of the reviewed works considered the intelligence level and only few considered the design level of the decision-making by considering the need for services adaptations in order to make them cloud enabled. For example, Andrikopoulos et al. [4] considered the adaptation required for migration applications to the cloud.

Further, the review shows a high level of interest in supporting the migration for the IaaS model followed by the SaaS while very limited support to the PaaS. Additionally, existing approaches focus on the migration from on-premises to the cloud while there is a lack of support for the migration between cloud providers. This is an important aspect to be addressed to avoid the issue of vendor lock-in which is a concern for many [35].

In addition, the tasks required for the decision to migrate to the cloud are usually beyond organisations' capabilities or knowledge. Further, the majority of the existing DSSs are conceptual or experimental prototype-based. Therefore, improving the efficiency of the decision to migrate would require automating the migration tasks.

Another problem with the current approaches is the separation of important aspects of the migration process that are connected and dependent on each another. Additionally, the range of information required to be considered for migration is increasing as a result of the development of the technology and expansion of the services offered. Further, the availability of a wide range of DSSs and cost calculation tools may create uncertainty for decision makers, if they are used outside of a systematic process.

The next section reviews three models designed for providing a migration process.

\section{PROCESS MODELS FOR MIGRATING TO THE CLOUD}

Beserra et al. [36] proposed a step-by-step cloud decision process to support the migration of legacy applications to the cloud that comprises nine activities. The process relies on the creation of template based profiles characterising the organisation, the target legacy application, and candidate cloud providers. These are then cross-analysed to help in identifying and possibly resolving critical constraints. This idea may make it easier for developers to find an existing cloud migration solution whose characteristics closely match the organisation. However, there are a number of limitations in this process. It primarily focuses on supporting software developers whereas cloud migration is a business driven decision that involves organisational risks much more than just the technical aspects. The analysis of applications does not include major tasks, such as integration requirements and the main standards and regulation. This can be problematic, especially in the case of hybrid deployment scenarios. In addition, the separation between the creation of profiles and constrain analysis might be time consuming. Further, the mechanism of how the templates will be stored and how to select the candidate cloud provider is not specified.

Jamshidi et al. [37] introduced the Cloud-RMM reference model that aimed to enhance the cloud migration process. It identifies the key processes related to cloud migration, based on the analysis and combination of the existing cloud DSSs. The model includes four main processes. Process 1 - Migration Planning: It includes a number of initial tasks such as feasibility study and migration requirement analysis. In addition, it includes deciding which provider should be chosen, which subsystems should be migrated, which cloud services should be used, and finally the development of the migration strategy. Process 2 - Migration Execution: This is where the actual migration tasks such as data extraction, architecture recovery and adaptation as well as code modification and wrapping, and legacy-to-cloud transformation at both conceptual and concrete levels are executed. Process 3 Migration Evaluation: This takes place when the migrated system is ready for use and requires validation. In this process, tasks such as testing validation and deployment of migrated applications are performed. Process 4 - Crosscutting concerns: This is where the tasks including governance, security analysis, training, effort estimation, organisational change, multi-tenancy, and elasticity analysis are performed. Jamshidi et al. [37] concluded that cloud migration research is still in the early stages of maturity. They identified the need for a comprehensive framework that supports the migration process. The cloud-RMM reference model provides a foundation for a process that combines DSS and tools; however it lacks a systematic procedure for utilising them.

Conway and Curry [38] developed a lifecycle model to manage cloud migration projects. It aims to aid organisations in assessing and controlling their migration projects and also their on-going management in the cloud environment. The model applies an approach that measures organisations maturity to migrate and manages services in the cloud environment. The model includes four phases that are extended to nine steps:

Phase 1: Architect - this phase includes the identification of the organisation's objectives, an assessment of suitable applications for outsourcing, evaluating the impact on the current delivery model, and the definition of strategies for staffing, organisational rules, program roll-out, risk assessment, integration, and monitoring. Phase 2: Engage - the purpose of this phase is to select a service provider that can deliver the required cloud service detailed during the architect phase. Phase 3: Operate - this phase is the implementation and management of the cloud service, which includes managing the transition, the impact on staffing level and adapting accordingly, communication to all stakeholders, and the acceptance sign-off. Phase 4: Refresh - this phase is the continuing review of cloud-based services performance.

The life cycle model provides organisations with a structure that assists them in understanding and assessing their systems' maturity and helps them to evaluate, implement, and manage services in the cloud environment. However, the main limitation of this model is that it is a high-level structure. Although the model has been successfully applied in some migration projects, it was observed that significant details are required in order to sufficiently address the cloud problems [39]. For example, in the second phase (selecting cloud providers) the approach did not specify the mechanisms for evaluating and selecting providers. Moreover, this model focuses on managing the transitions to the cloud while it is not always certain that the cloud is more effective than the in-house deployment. Therefore, organisations need further support at the planning stage to assess whether cloudbased services provide the solution for their requirements. The support should also include comprehensive details about the tasks to be performed at each step. 


\section{INTELLIGENCE LEVEL}

There is increasing agreement that decision processes should not be a matter of a simple choice [40], and that the role of information (intelligence) and the construction of potential alternatives are essential. Information is particularly fundamental in the first two phases of a decision making process because alternatives can only be chosen where there is sufficient and documented information about the available options. Information acts as a constraint on decision making. Lack of information has been a weakness in many of the existing DSSs. This is because many designers place emphasis on the models they build into their systems rather than on the significance of the information fed into them [41].

Based on the complexity of migration to the cloud discussed in section 2.3, making informed migration decisions would require gathering information at the intelligence level of the decision making process [9]. It requires an assessment of the environment in which the system is currently operating in to define the cloud migration strategy. It should include: the intention of migration, clear objectives, requirements and constrains, and a description of the current operation and infrastructure. These would require an understanding of organisations' characteristics and an assessment of the organisational innovation culture, trends and the competitive environment. In this level organisations can be supported by developing an organisational profile that describes the factors that might be important to consider while planning for migration. These include: staffing, the current IT infrastructure (hardware, applications, network architecture) and management, financial constraints, the business strategy and objectives, security and privacy, organisational structure and the business units.

At the intelligence level also, decision makers are required to gather information about the cloud environment. The purpose of this is to aid decision makers in acquiring the knowledge they need prior to the migration. It would allow them to identify opportunities, capabilities, potential risks, offering models, suitable configurations, level of support, risks, pricing models, potential providers, and the expertise required to manage applications in the cloud environment. It is important to realise these aspect at early stages of a decision making process in order to avoid the confusion about the cloud environment [42]. It will also aid enterprises in enhancing trust in cloud environment and ensuring transparency. Organisations could define service management metrics that are suitable for the cloud computing environment. Developing knowledge about the cloud environment will also aid organisations in ensuring an appropriate Service Level Agreement (SLA) which is a vital aspect in cloud computing. SLAs include agreements regarding to quality of service attributes, pricing, compliance to regulation, level of support, security and privacy guarantees, and others. Organisations need to review the general terms and conditions that cloud providers usually include in SLAs.

The review of the existing approaches discussed in sections 3 and 4 shows that there is a lack of a comprehensive decision support process. Particularly, there is limited consideration of the intelligence level for the decisions to migrate to the cloud. Therefore, sections 5.1 and 5.2 discuss two main approaches that provide consideration at the intelligence level that can potentially address the complex issues in the process of migration decisions.

\subsection{Knowledge-based Decision Support Systems (KBDSS)}

Supporting decisions at the intelligence level requires a process for collecting information to assist each phase of the decision making. March and Hevner [43] pointed out that successful support for decision-making is critically dependent upon the availability of integrated, high quality information that is organised and presented in a timely and easy to understand manner. Some of the cloud DSSs utilise knowledge-bases that provide cloud offerings along with their pricing policies as discussed in [19] and [20]. However in the context of migration to the cloud, a wider range of information such as cloud capabilities, services offered, pricing schemes, etc., should be considered. This will aid organisations to identify opportunities and services that can help to improve business processes and operation.

The range of information required for consideration in the decision-making process for migrating need to be augmented by the existing cloud migration tools for analysis of applications and the selection of providers. This could be achieved through the application of KBDSS. They can be defined as computer information systems that support the making of effective decisions in complex and ill structured problem domains by assisting with knowledge storage and retrieval, the interpretation of various alternatives, and providing methodological knowledge by using analytical decision models [44]. Knowledge-driven DSSs can suggest actions to managers. They are human-computer systems with specialised problem-solving expertise. In a highly dynamic environment, KBDSS can be the solutions to whether an organisation can obtain the right information to the right people in the right form at the right time [45]. The 'expertise' consists of knowledge about a particular domain, understanding of problems within that domain, and 'skill' at solving some of these problems [46]. The likely advantages of knowledge-based systems include: an improvement in the speed and quality of responses to events, improved acquisition of resources, and enhanced control of strategic planning. Further, the use of KBDSS has been proven to be an appropriate approach to support decision making in IT projects [47]. On the other hand, the implementation of knowledge management systems is difficult and also very little guidance exists [45]. This is mainly because of the ambiguity associated with the implementation technique and the fact that knowledge systems are processes to follow rather than systems of specific procedures [48]. Further, the cost of developing knowledge systems is usually high [45].

\subsection{Collaborative DSS}

Recently, there is an increasing interest in the design of collaborative and intelligent society of agents that are capable of addressing complex problems and vast amounts of information [49]. The increasing growth of DSSs, tools, and information can be exploited by forming a collective decision-making in which decision makers share the context and make decisions based on the opinions of other members within a global network of brains [50].

Group Decision Support Systems (GDSS) is an effort to facilitate an environment for collaborative decisions [51]. DeSanctis and Gallupe define GDSS as "an interactive, computer-based system that facilitates unstructured problem solving by a set of decision factors working together as a group" [52]. The collaboration in GDSS in which a larger number of stakeholders can efficiently and effectively participate in the decision making process is likely to lead to improved decisions [50]. GDSS focuses on the use of 
meeting systems in order to support the generation of ideas and decision making in small group settings [51]. It aims to remove communication barriers; provides decision modelling and group decision techniques to reduce uncertainty in the group decision process; as well as improving group decision patterns through expert advice [52].

The collaboration functionality of GDSS can be enhanced through the advances of databases, artificial intelligence, operational research, and particularly the development of web technologies. They facilitate the introduction of 'web-based collaborative decision' [53]. They are commonly known as Web 2.0 and Semantic Web (Web 3.0) which introduces an improved ability to connect and organise the content of information distributed across multiple pages or sites [52]. This includes the application of social networks that can be used for decision-making sharing and consensus or voting process within specific contexts [50]. In 'web-based collaborative decision' several entities (humans and machines) liaise to reach an acceptable decision. The entities are distributed and possibly mobile along networks [49]. Ensuring a collaboration of the entities requires: removing communication difficulties, and providing techniques for structuring the decision analysis and systematically directing the pattern, timing, or content of the related decisions [54].

The advances in these technologies can be exploited in a way that allow decision makers to address the increasingly dynamic and complex process of migrating to the cloud. Particularly, the support required at the intelligence phase of migration decisions. The intelligence phase consist of finding, sharing, and analysing information. Application of web-based collaboration tools and GDSS is to search as well as aid in sharing information among participating group members. They can increase the efficiency of gathering information and its distribution [51].

\section{CONCLUSION}

Cloud computing is a new paradigm for emerging technology in the computing and IT industries. It offers ready-to-consume IT services that can enhance business agility and reduce costs. Migration to cloud computing is a strategic organisational decision that can be complicated, dynamic, and highly unstructured. This is due to the heterogeneity of organisational systems, the increasing number of cloud providers and their configurations, as well as the still evolving nature of cloud computing in which many issues such as security and vender lockin still unresolved.

This review paper focused on the recent DSSs designed to aid the decisions for migrating to the cloud. It reveals that the level of support they offer is not sufficient to enable decision makers in making informed decisions. This is mainly because of the underestimation of the factors affecting the decision making for cloud migration in which the support is usually limited to the choice of cloud providers. They often lack information about the cloud environment, and provide a limited amount of the information needed by organisations to assess the suitability of their own services for the cloud. Therefore, a comprehensive support for the decisions of migration cannot be limited to the evaluation of cloud services providers.

The analysis also shows that decisions being made without considering the whole process lead to less informed decisions and possibly resulting in higher risk of failure. This paper analysed three models designed to provide a process for migrating to the cloud. These models have limitations, which result in a coherent process, that covers the whole decision aspects and explicitly describes the migration steps and tasks is still missing.

Therefore, this paper calls for new approaches for supporting the decision-making process for migrating to the cloud. New approaches should pay specific attention to the tasks required during the intelligence and design phases which have been neglected by existing approaches that are in favour of vendors' evaluation. They should also enable decision makers to effectively exploit a wide range of the existing cloud migration DSSs in a collaborative manner.

This paper highlights the importance of the intelligence level as a key factor to ensure successful migration decisions. It suggests the application of KBDSS and collaborative DSS as potential solutions to address the complexity of the decision-making process for cloud migration. Developing such systems would require a framework for integrating the required cloud DSSs with knowledge management processes including, discovery and detection of trends and patterns, and knowledge acquisition, application, and sharing.

\section{REFERENCES}

[1] Armbrust, M., Fox, A., Griffith, R., Joseph, A. D., Katz, R., Konwinski, A. and Zaharia, M. 2010. A view of cloud computing. Communications of the ACM, 53, 4, 50-58.

[2] Sahandi, R., Alkhalil, A. and Opara-Martins, J. 2013. Cloud Computing from SMEs perspective: a Survey based Investigation. Journal of Information Technology Management. 24, 1, 1-12.

[3] Buyya, R. 2009. Market-oriented cloud computing: Vision, hype, and reality of delivering computing as the 5th utility. 9Th IEEE/ACM International Symposium On Cluster Computing And The Grid, CCGRID 2009.

[4] Andrikopoulos, V., Binz, T., Leymann, F. and Strauch, S. 2013. How to adapt applications for the Cloud environment. Computing. 95, 6, 493-535.

[5] Khajeh-Hosseini, A., Greenwood, D., Smith, J., and Sommerville, I. 2012. The Cloud Adoption Toolkit: Supporting cloud adoption decisions in the enterprise. Software - Practice And Experience. 42, 4, 447-465.

[6] Rashmi, Sahoo, G. and Mehfuz, S. 2013. Securing Software as a Service Model of Cloud Computing: Issues and Solutions. International Journal on Cloud Computing Services.

[7] Architecture, Gonidis, F., Paraskakis, I. and Simons, A. J. 2014. Leveraging Platform Basic Services in Cloud Application Platforms for the Development of Cloud Applications. IEEE 6th International Conference on Cloud Computing Technology and Science. 751-754.

[8] Chang, S.E., Kuo-Ming C., and Yu-Ching C. 2015. Cloud migration: Planning guidelines and execution framework. In Ubiquitous and Future Networks (ICUFN), 2015 Seventh International Conference. 814-819.

[9] Simon H. A. 1977. The new science of management decision, 2nd Edition, Prentice Hall, Englewood Cliffs (NJ).

[10] Liu, S., Duffy, A., Whitfield, R. and Boyle, I., N. D. 2010. Integration of decision support systems to improve decision support performance. Knowledge And Information Systems. $22,3,261-286$. 
[11] Turban, E. Aronson, J. and Liang, T. P. 2005. Decision Support Systems and Intelligent Systems. 7 Edition. Pearson Prentice Hall.

[12] Pahl, C., Xiong, H. and Walshe, R. 2013. A comparison of on-premise to cloud migration approaches. In: European Conference on Service-Oriented and Cloud Computing ESOCC. 11-13.

[13] Saripalli, P. and Pingali, G. 2011. MADMAC: Multiple attribute Decision methodology for Adoption of clouds. Proceedings - 2011 IEEE 4Th International Conference On Cloud Computing, CLOUD 2011.323.

[14] Khajeh-Hosseini, A., Sommerville, I., Bogaerts, J. and Teregowda, P. 2011. Decision support tools for cloud migration in the enterprise. Proceedings - 2011 IEEE 4th International Conference on Cloud Computing, CLOUD. 541-548.

[15] Dhinesh Babu, L. D., Gunasekaran, A., and Krishna, P. V. 2014. A decision-based pre-emptive fair scheduling strategy to process cloud computing work-flows for sustainable enterprise management. International Journal of Business Information Systems. 16, 4, 409-430.

[16] Fink, D. and Shoeib, A. 2000. Key Decision-Making Phases and Tasks for Outsourcing Information Technology. PACIS 2000 Proceedings, 774-184

[17] Menzel, M., Ranjan, R., Wang, L., Khan, S. and Chen, J. 2014. Cloudgenius: A hybrid decision support method for automating the migration of web application clusters to public clouds. IEEE transactions on, 64, 5, 1336-1348.

[18] Andrikopoulos, V., Strauch, S. and Leymann, F. 2013. Decision Support for Application Migration to the Cloud. Proceedings of CLOSER'13, 149-155.

[19] Andrikopoulos, V., Sáez, S. G., Leymann, F., and Wettinger, J. 2014. Optimal distribution of applications in the cloud. In Advanced Information Systems Engineering. Springer International Publishing.75-90.

[20] Menzel, M. and Ranjan, R. 2012. CloudGenius: Decision support for web server cloud migration. $W W W^{\prime} 12$ Proceedings of the 21st Annual Conference on World Wide Web. 979-988.

[21] Motahari-Nezhad, H. R., Stephenson, B. and Singhal, S. 2009. Outsourcing business to cloud computing services: Opportunities and challenges. IEEE Internet Computing, 10.

[22] Omerovic, A., Muntes-Mulero, V., Matthews, P. and Gunka, A. 2013. Towards a Method for Decision Support in Multicloud Environments. In the fourth International Conference on Cloud Computing, GRIDs, and Virtualisation. 244-250.

[23] CSA. 2013. Practices for Secure Development of Cloud. Cloud security Alliance. DOI= http://www.safecode.org/publications/SAFECode_CSA_Clo ud_Final1213.pdf.

[24] Garg, S. K., Versteeg, S. and Buyya, R. 2013. A framework for ranking of cloud computing services. Future Generation Computer Systems. 626, 4, 1012-1023.

[25] García-Galán, J., Trinidad, P., Rana, O. F. and Ruiz-Cortés, A. 2016. Automated configuration support for infrastructure migration to the cloud. Future Generation Computer Systems. 55, 200-212.DOI=
http://www.sciencedirect.com/science/article/pii/S0167739X 15000618 (Accessed 1 June 2015).

[26] Bergmayr, A., Bruneliere, H., Canovas Izquierdo, J. L., Gorronogoitia, J., Kousiouris, G., Kyriazis, D. and Wimmer, M. 2013. Migrating legacy software to the cloud with ARTIST. In IEEE Software Maintenance and Reengineering (CSMR), 2013 17th European Conference on. 465-468.

[27] Juan-Verdejo, A., Baars, H., Kemper, H., Surajbali, B. and Zschaler, S. 2014. InCLOUDer: A formalised decision support modelling approach to migrate applications to cloud environments. Proceedings - 40Th Euromicro Conference Series On Software Engineering And Advanced Applications, SEAA. 67-474.

[28] Santiago, G. 2015. Performance and Cost Evaluation for the Migration of a Scientific Workflow Infrastructure to the Cloud. 5th International Conference of Cloud Computing and Service Science, CLOSER 2015. Lisbon, Portugal. 1-10.

[29] Menzel, M., Schönherr, M. and Tai, S. 2013. (MC2) 2: criteria, requirements and a software prototype for Cloud infrastructure decisions. Software: Practice and Experience, 43, 11, 1283-1297.

[30] Andrikopoulos, V., Song, Z. and Leymann, F. 2013. Supporting the Migration of Applications to the Cloud through a Decision Support System. IEEE Sixth International Conference On Cloud Computing, 565-572.

[31] Strauch, S., Andrikopoulos, V. and Karastoynova, D. 2014 Migrating Enterprise Applications to the Cloud: Methodology and Evaluation. International Journal Big Data Intelligence, 1, 127-140.

[32] Juan-Verdejo, A. and Baars, H. 2013. Decision support for partially moving applications to the cloud: the example of business intelligence. In Proceedings of the 2013 international workshop on Hot topics in cloud services, ACM. 35-42.

[33] Frey, S. and Hasselbring, W. 2011. The cloudmig approach: Model-based migration of software systems to cloudoptimized applications. International Journal on Advances in Software, 4, 3 and 4, 342-353.

[34] Misra, S. and Mondal, A. 2011. Identification of a company's suitability for the adoption of cloud computing and modelling its corresponding Return on Investment. Mathematical And Computer Modelling, 53, 3. 504-521.

[35] Opara-Martins, J., Sahandi, R. and Tian, F. 2014. Critical review of vendor lock-in and its impact on adoption of cloud computing. On IEEE Information Society (i-Society), 2014 International Conference. 92-97.

[36] Beserra, P. V., Camara, A., Ximenes, R., Albuquerque, A. B., and Mendonca, N. C. 2012. Cloudstep: A step-by-step decision process to support legacy application migration to the cloud. 6th International Workshop on the (MESOCA), IEEE, pp. 7-16.

[37] Jamshidi, P., Aakash A. and Claus, P. 2013. Cloud migration research: a systematic review. IEEE Transactions on Cloud Computing. 1, 2, 142-157.

[38] Conway, G. and Curry, E. 2012. Managing cloud computing: A life cycle approach. CLOSER 2012 - Proceedings of The $2 N d$ International Conference On Cloud Computing And Services Science, 198-207. 
[39] Conway, G., Carcary, M. and Doherty, E. 2015. A Conceptual Framework to Implement and Manage a Cloud Computing Environment. CLOUD COMPUTING 2015: The Sixth International Conference on Cloud Computing, GRIDs, and Virtualisation. 122-126.

[40] Langley, A., Mintzberg, H., Pitcher, P., Posada, E. and SaintMacary, J. 1995. Opening up Decision Making: The View from the Black Stool. Organisation Science, 3, 260

[41] Diniz, V. B., Borges, MRS, Gomes, J. O. and Canos, J. H. 2008. Decision making support in emergency response. Encyclopedia of decision making and decision support technologies, 1, 184-191.

[42] Mckendrick, J. 2014. What Cloud Computing Customers Want: Clarity, Simplicity, Support. DOI= http://www.forbes.com/sites/joemckendrick/2014/07/19/what -cloud-computing-customers-want-clarity-simplicity-support/ (Accessed 22/10/2015).

[43] March, S. and Hevner, A. 2007. Integrated decision support systems: A data warehousing perspective. Decision Support Systems, 43, Integrated Decision Support, 1031-1043.

[44] Klein, M. R. and Methlie, L. B. 1995. Knowledge-based DSS with applications in business. 2nd edition. New York (NY USA): John Wiley \& Sons, Inc.

[45] Sauter, V. and Free, D. 2005. Competitive intelligence systems: Qualitative DSS for strategic decision making. Data Base for Advances In Information Systems, 36, 2, 43-57.
[46] Power, D. J. 2002. Decision Support Systems: Concepts And Resources For Managers / Daniel J. Power, n.p.: Westport, Conn.: Quorum Books, 2002.

[47] Zaraté, P., IRIT, F. and Liu, S. 2015. A New Trend for Knowledge Based Decision Support Systems Design. International Journal of Information and Decision Sciences

[48] Oxbrow, N. 1998. Knowledge Management: A New Competitive Asset, New York: Special Libraries Association.

[49] Adla, A., Nachet, B. and Ould-Mahraz, A. 2012. MultiAgents Model for Web-based Collaborative Decision Support Systems. In ICWIT. 294-299.

[50] Brandas, C. and Didraga, O. 2014. Collaborative decision systems: cloud, mobile, and social approaches. The 13th International Conference on Informatics in Economy (IE 2014)

[51] Turban, E., Liang, T.P. and Wu, S.P. 2011. A framework for adopting collaboration 2.0 tools for virtual group decision making. Group decision and negotiation, 20, 2, 137-154.

[52] DeSanctis, G. and Galluoe, B. 1987. A Foundation for the study of Group Decision Support Systems. Management Science. 589-609.

[53] Antunes, F. and Costa, J.P. 2012. Integrating decision support and social networks. Advances in Human-Computer Interaction, 9.

[54] Karacapilidis, N. and Papadias, D. 2001. Computer supported argumentation and collaborative decision making: the HERMES system. Information systems, 26, 4, 259-277. 